\title{
(HIPER)TEXTOS CIBERESPACIAIS: MUTAÇÕES DO/NO LER-ESCREVER
}

\author{
Sérgio Roberto Costa*
}

\begin{abstract}
RESUMO: O espaço da internet possui novas formas de escrita e leitura com características específicas que provocam mutaçôes no/do ler/escrever, as quais escapam à sucessividade canônica das ferramentas ou dos suportes de escrita tradicionais. Nosso objetivo é discutir e analisar essas mutaçōes, em razão da emergência de novos gêneros discursivos e textuais, produtos histórico-sociais construídos no computador. $\mathrm{Na}$ análise, focalizamos a relação enunciativo-discursiva da ferramenta, do suporte, dos dispositivos, da materialidade do código, do espaço enunciativo e da arquitetura hipertextual com algumas formas de comunicação (correio eletrônico, fóruns, chats...) e com a navegação (produção e compreensão) hipertextual, com base em dois conceitos de gêneros: os discursivos de Bakhtin (1953/1994) e os textuais de Bronckart (1999). Pudemos concluir que características lingüístico-discursivas e enunciativas de várias ordens, ligadas à ferramenta, ao suporte e a seus dispositivos, ao modo de comunicação hipertextual e ao espaço enunciativo virtual, levaram-nos a apontar o surgimento de novos gêneros e novas estratégias de ler/escrever.
\end{abstract}

Palavras-chave: Internet. Ciberespaço. Gêneros. Hipertexto. Ler/escrever.

\section{Cyberspace (HYPERT)TEXTS: READING-WRITING MUTATIONS}

ABSTRACT: The internet space has new forms of writing and reading with specific characteristics that provoke changes in the reading and writing that differ from the canonical progressiveness of the tools or the traditional writing gadgets. Our goal is to discuss and analyze these mutations, considering the emergence of new discursive and tex-

\footnotetext{
Doutor (em Lingüística Aplicada ao Ensino de LM) pela Pontifícia Universidade Católica de São Paulo (PUC-SP), professor adjunto aposentado da Universidade Federal de Juiz de Fora (UfJF), professor do Mestrado em Letras da Universidade do Vale do Rio Verde (UNINCOR) Três Coraçôes (MG); professor coordenador do Curso de Letras da Faculdade de Filosofia, Ciências e Letras Santa Marcelina (FAFISM) - Muriaé (MG). E-mail: costasero@uol.com.br
} 
tual genres, historic-social products made in the computer. In the analysis, we focus on the enunciative-discursive relation of the tool, of the support, of the mechanisms, of the code materiality, of the enunciative space of the hypertextual architecture with some forms of communication (email, forums, chats...) and with the navigation (production and understanding) hypertextual, as of two concepts of genres: The Bakhtin's discursive (1953/1994) and the Bronckart's textual (1999). We could conclude that discursive-linguistic and enunciative characteristics of various orders, linked to the tool, to the support and their gadgets, to the way of hypertextual communication and to the virtual enunciative space, have taken us to point out the emergence of new genres and new strategies of reading and writing.

Key words: Internet. Cyberspace. Genders. Hypertext. Reading/writing.

\section{Introdução}

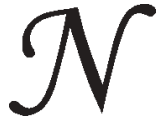

a internet, espaço de novas tecnologias digitais de leitura e escrita, leitor e escritor encontram-se diante de novos processos de produção e compreensão textuais. São formas de leitura e escrita com características próprias e específicas. Leitor e autor confundem-se nos (hiper)textos, produzidos/construídos sem fronteiras nítidas, misturando formas, processos e funçôes da oralidade, da leitura e da escrita. Leitor e autor/escritor cruzam-se, on-line, participando da edição do texto que lêem e escrevem, utilizando uma linguagem multissemiótica (Costa, 2000). Há mutações do/no ler e escrever que escapam, muitas vezes, à sucessividade canônica das ferramentas ou dos suportes de escrita tradicionais: na internet, o autor/escritor pode intervir na forma tipográfico-digital do seu texto e há uma aceleração geral da escrita.

Discutimos e analisamos as mutaçōes do/no ler/escrever nesse novo espaço, em razão da emergência de novos gêneros discursivos e textuais, produtos histórico-sociais que circulam em um novo suporte eletrônico. Segundo Maingueneau (1996), o suporte desempenha um papel fundamental na emergência e na estabilização de um gênero. Em nossa discussão, partimos de três pressupostos. As ferramentas (o computador, o teclado, os programas de interface), o suporte (a tela) e os dispositivos (meios eletrônicos) oferecem recursos técnicos que nos permitem comunicações e organizações e construções textuais, cuja arquitetura (hiper)textual é sui generis. A materialidade do código (conjunto de recursos icônicos, 
semióticos, logográficos, tipográficos, telemáticos), a arquitetura hipertextual (estrutura de rede "recomponível" e recomposta) e o espaço enunciativo (re)enquadrado, aliados à ferramenta, ao suporte e a seus dispositivos, são responsáveis pelo surgimento de novos gêneros discursivos e textuais e de novas variedades de linguagem, expressas por uma escrita de plasticidade e heterogeneidade diferentes das tradicionais, e provocam mudanças no ler/escrever. A leituralescrita de (hiper)textos virtuais de estrutura reticular que circulam na internet pode exigir estratégias (meta)cognitivas diferentes das da leitura/escrita do texto-papel linear.

Focalizamos a relação enunciativo-discursiva das ferramentas, do suporte, dos dispositivos, da materialidade do código, do espaço enunciativo e da arquitetura hipertextual com algumas formas (gêneros) de comunicação (e-mails, fóruns) e com a navegação hipertextual, a partir dos enfoques teóricos ligados a gêneros discursivos e textuais de Bakhtin e Bronckart. Para Bakhtin (1994), os gêneros encontram-se nas práticas sociais da linguagem, são muito variados e de grande amplitude, fazem parte do cotidiano dos interlocutores e desenvolvem-se com as experiências adquiridas no curso da História. Para Bronckart (1999), a dimensão textual subordina-se à dimensão discursiva produzida/construída na interação verbal. Neste caso: a) os gêneros textuais - orais ou escritos são produtos histórico-sociais, existindo diferentes tipos de acordo com os interesses e as condições de funcionamento das formações sociais; b) a emergência de novos tipos de gêneros textuais pode estar ligada à aparição de novas motivaçôes sociais e circunstâncias de comunicação ou a novos suportes de comunicação; c) os gêneros textuais estão em movimento perpétuo: desaparecem, voltam sob formas parcialmente diferentes, ou surgem novos gêneros; d) não se pode estabelecer claramente as fronteiras entre eles, já que constituem uma espécie de "nebulosa" (Bronckart, 1999, p. 74) para os usuários de uma língua. Entretanto resultado histórico-social de transformações de tipos precedentes - os gêneros textuais possuem características individuais, constituindo-se em um objeto sempre único.

Nessa perspectiva sócio-histórica, na produção de um gênero haverá sempre uma interação determinada e regulada pela organização enunciativa da situação de produção, que é definida por alguns parâmetros sociais: o lugar social da interação (sociedade, instituição, esfera cultural, tempo histórico); os lugares sociais dos interlocutores ou enunciadores (relaçõos hierárquicas e interpessoais, relações de poder e 
dominação...); e finalidades da interação (intenção comunicativa do enunciador). Além disso, a forma composicional (formas dos enunciados), as marcas lingüisticas (formas da língua) e o estilo (escolhas lingüísticodiscursivas) dependem do gênero a que pertence o texto, e esse gênero operante dependerá da situação da enunciação em curso na operação.

As novas características lingüístico-discursivas e enunciativas, ligadas ao suporte, à ferramenta e a seus dispositivos, ao modo de comunicação (hiper)textual e ao espaço enunciativo virtual, levaram-nos a apontar o surgimento de novos gêneros, ou seja, o computador seria o mediador que modificaria o discurso e levaria à criação de outros gêneros textuais e a novas maneiras de ler/escrever.

\section{A ferramenta, o suporte e os dispositivos: novas formas de ler/ escrever}

A revolução tecnológica não começou com o advento dos computadores pessoais, mas há muito tempo. Novos materiais (papiro, pergaminho, papel) ou novas ferramentas (estilete, pena de ganso, canetas, borracha, máquina de escrever, imprensa tipográfica, máquinas fotocopiadoras, computadores) ou produtos tecnológicos que chamamos de portadores/suportes de textos (rolo de papiro, tablete de cera, códex, livro impresso, CD-ROM, home pages e websites na internet) são tecnologias culturais, procedimentos e dispositivos que, cada um a seu tempo, transformaram as relaçôes com o outro, com os conhecimentos e o saber, com a escritura e a leitura.

Mas "o computador é, entretanto, o catalisador de uma transformação maior que, dissociando o texto de suas encarnações materiais, dálhe uma plasticidade e uma mobilidade desconhecidas até agora" (Anis \& Marty, 2000, p. 11). Em outras palavras, todos esses materiais, ferramentas e produtos tecnológicos subverteram os processamentos de tex$\operatorname{tos}^{2}$ e as novas formas de comunicação e mesmo o conteúdo transmitido. Segundo Goody (1997, p. 46), "mesmo que não possamos reduzir razoavelmente uma mensagem ao meio material de sua transmissão, toda mudança de sistema de comunicação tem necessariamente importantes efeitos nos conteúdos transmitidos". Podemos acrescentar: a mudança de ferramenta, de suporte ou dos dispositivos implica mudanças sobre o processo de escrita. Nós não escrevemos da mesma maneira à mão, à 
(Hiper)textos ciberespaciais: mutações do/no ler-escrever

máquina de escrever tradicional ou elétrica e com o computador. Com o computador, ou com o processamento de textos, a revolução é ainda maior. Em quatro decênios e em menos de cinco gerações de material, a informaçáo chegou a se tornar um modo de escritura novo e o denominador comum de todos os sistemas de escritura constituindo-se, talvez, como a primeira escritura universal (Vuillemin, 1990). Também Anis \& TemporalMarty (1990) destacam essa universalidade, quando afirmam que a informática, mesmo se reduzindo a um alfabeto de dois caracteres, 0 e 1 , pode processar hoje todos os tipos de escritura, inclusive os ideogramas orientais.

Neste sentido, Hudrisier \& Hudrisier (2000) falam de um paradigma - "codificação discreta", composto de elementos separados, no sentido matemático - diferente do paradigma estruturante de textos, introduzido pelo alfabeto grego com vogais, pela passagem do volumen ao códex e pela introdução do papel no século XI. Esse paradigma levou a humanidade para o caminho das sociedades informatizadas e do texto numerisado, que fez o texto perder o espaço-livro e o espaço-papel. As especificidades da escrita numérica, conseqüentemente, devem ser levadas em conta em razão da virtualidade e da imaterialidade do texto informatizado e do modo de estruturação hipertextual das informações.

Mediada pela ferramenta (componentes técnicos, periféricos de entrada - mouse, canetas ópticas, microfone, escâner) e pelos dispositivos (programas, recursos de interfaces de diálogo virtual: ícones para clicar, cursores dinâmicos, zonas sensíveis, efeitos visuais e sonoros), concentrados no micro ou interligados por cabos, a escrita torna-se fluida, imaterial. Nesta perspectiva, podemos dizer que o espaço virtual permite ao usuário modificar o texto a seu bel-prazer: corrigir, cortar e colar, limpar, inserir, editar, formatar, movimentar elementos. Podemos ler e escrever ao mesmo tempo. Somos escreventes e escritores ao mesmo tempo. Escrever é ler. Ler é escrever.

O texto eletrônico não é senão um conjunto de signos escritos sob a forma de sinais elétricos que podem sofrer toda sorte de modificações, tornando-se realmente um texto somente quando o computador nos tiver decodificado esses sinais. Segundo Anis \& Marty (op. cit., p. 16), esse texto só existe em função dos impulsos elétricos armazenados na memória e dos feixes de luz na tela. Esta virtualidade ou imaterialidade contrasta com a permanência e a durabilidade relativa de uma incisão na pedra ou da tinta no papel. 
Esta liberdade do texto numérico, ou melhor, esta "desterritorialização" ou "desmaterialização" provocou, na opinião de Clément (2001), três conseqüências: a disseminação dos textos; a desconstrução dos suportes/portadores tradicionais de textos: a biblioteca e o livro; a convergência com as outras mídias. A essas três conseqüências acrescentaríamos uma quarta: o surgimento/nascimento de novos gêneros discursivos e textuais.

Até aqui abordamos quase que exclusivamente os aspectos materiais, técnicos, do processo de escrever e ler textos numéricos. Mas faltanos mostrar que as mudanças do processo de escrita/leitura, mediadas pela ferramenta, pelo suporte e pelos dispositivos informáticos, podem provocar a origem e a estabilização de novos gêneros discursivos, com implicações em sua complexidade lingüística e enunciativa.

Sem dúvida, um novo meio tecnológico interfere na estabilização e na natureza dos gêneros produzidos em determinadas situações históricas, sociais e culturais, e não é difícil de se descrever a relativa estabilidade composicional e estilística (Bakhtin, 1994) de um gênero utilizado como ação social e comunicativa.

A organização espacial enunciativa, que a ferramenta e os programas oferecem, abre possibilidades de produção e recepção originais. $\mathrm{O}$ espaço da escrita numérica, dinâmica e interativa, autoriza e estimula as interaçôes entre autor-leitor-texto. Porém trata-se de um modo de comunicação e de uma situação de enunciação complexos, que se desenrolam num espaço enunciativo também complexo, que favorece a heterogeneidade enunciativa e receptiva, e, portanto, a produção de escritas de diversas naturezas, inclusive a emergência de novos gêneros.

Muitos pesquisadores de textos produzidos na internet apontam o nascimento de alguns novos gêneros, os quais, embora tenham semelhanças com gêneros já existentes, não são os mesmos. Assim, mesmo utilizados na comunicação interindividual, o e-mail é diferente da carta, o chat é diferente de uma conversa face a face ou telefônica. Concretamente, podemos dizer que um e-mail não é uma carta, nem um fax, nem uma chamada telefônica, mas um gênero textual original, com qualidades lingüísticas, enunciativas, discursivas e pragmáticas próprias. Ele é mais rápido que a correspondência postal comum, menos caro que o telefone, fácil de ser utilizado. Seu tom é coloquial e direto; não há perda de tempo, nem fórmulas convencionais. Vai-se diretamente ao assunto, sem a obrigatoriedade de começos formais. Diferentemente do fax, o e- 
(Hiper)textos ciberespaciais: mutações do/no ler-escrever

mail permite que se modifique um texto enviado, com sobreposições de discursos, pois há possibilidades técnicas para fragmentar e divulgar uma mensagem em diversos espaços. Para se editá-lo, tanto em termos de produção ou de recepção, basta copiar, colar ou cortar parte ou o todo do conteúdo de uma mensagem. As mensagens recebidas e enviadas são arquivadas automaticamente no computador e é possível se enviar ou encaminhar a mesma mensagem a vários destinatários ao mesmo tempo. Esse tipo de dispositivo permite ainda que pessoas interessadas em um mesmo assunto possam fazer uma discussão coletiva on-line, como nos fóruns. É possível, inclusive, enviar textos anexados. Neste sentido, o $e$ mail não se limita ao texto-mensagem, pois abre possibilidades de trocas de tabelas, de imagens, de gráficos, de brincadeiras e até de vídeos. Tudo isso em poucos segundos e sem problema com fusos horários. Podemos ainda acrescentar que, assim como existem graus de formalismo entre a correspondência tradicional, a chamada telefônica e a conversa, também existem entre o e-mail, os fóruns e os chats.

Essas diferenças anteriormente descritas se refletem na linguagem. Anis (2000 e 1999) diz que existe um consenso entre os pesquisadores de mensagens telemáticas sobre a hibridação lingüística aí presente. Trata-se de uma hibridação entre o oral e o escrito, de uma "escrita oralizada", de um "falar-escrito" ou de uma "escrita espontânea rápida" ${ }^{3}$

Como podemos ver, são as ferramentas (minitel, computador, celular) e os dispositivos (sistemas utilizados) que criam a instantaneidade, a rapidez da transmissão, e portanto a "imediaticidade" e a aceleração da circulação dos dados informativos com reflexos nas formas textuais e lingüísticas, provocando o nascimento de novos gêneros. Os chats ou outras formas de comunicação mediadas por minitel, computador ou celular alargam o campo da comunicação escrita e transformam competências técnicas em códigos culturais (Anis, 2000 e 1999). Trata-se de um "falar textos" que possui uma linguagem-código a qual produz um tipo de escrita que procura o equilíbrio entre o espaço ocupado na tela e o tempo usado. É a língua regida por um elementar princípio de economia.

\section{A materialidade do código: os novos gêneros e a "conversa-escrita"}

Um outro fator que nos leva a interpretar os textos produzidos na internet como novos gêneros textuais é o que vamos chamar de "materialidade do código" - um conjunto de recursos o qual constitui um novo 
código discursivo e cultural, espontaneamente construído pelos usuários da internet, principalmente nos e-mail e chats, quando fazem uso de ícones, de logogramas, topogramas, smileys (emoticons), sinais de pontuação, abreviações, alongamentos gráficos, combinações de sinais, usos de maiúsculas etc.

Esses recursos utilizados na web produzem a "conversa-escrita" ou o "falar-escrito". Trata-se da reutilização de recursos já existentes, específicos de certos gêneros textuais já utilizados, em novos gêneros que entram em circulação, e que vão se transformando e se modificando a partir de novas motivações sociais e circunstâncias de comunicação, produzidos por uma nova ferramenta de comunicação, o computador.

Esse "falar-escrito" ou "conversa-escrita" - centrado totalmente na escrita, numa relação síncrona e simultânea, em que não há mais defasagem entre a produção e a recepção, como na escrita tradicional - de mensagens eletrônicas veiculadas na internet, cujos léxicos prolongam ao infinito as possibilidades de combinar diferentes tipos de códigos, foi descrito e analisado por muitos pesquisadores. Mas há dois pontos comuns em estudos recentes destes temas. De um lado, o caráter híbrido (oralidade-escrita) dessas mensagens na internet e, de outro, o uso de topogramas, logogramas, combinações de sinais tipográficos, abreviações, emoticons, que visam a facilitar a redação de mensagens e assegurar a regulação dos diálogos na interação verbal e social na internet.

Panckhurst (1999) resumiu algumas características lingüísticas e extralingüísticas presentes no correio eletrônico, ${ }^{4}$ as quais possuem valores enunciativos, verbais ou paraverbais diversos. São recursos parecidos com os funcionamentos típicos de uma situação de comunicação oral e que nem sempre figuram em outros tipos de escrita, embora o diálogo literário, por exemplo, e sobretudo as revistas em quadrinhos façam uso desses tipos de recursos também. Analisando a escrita de chats, Anis (2000) resume, semelhantemente, essas características em três principais procedimentos: uso de sinais auxiliares particulares e adaptação da pontuação; grafias alternativas; particularidades lexicais.

Mesmo que alguns estudiosos sejam mais descritivos que outros ao analisar essa escrita, a maioria aponta uma identidade enunciativa nova em que os usuários utilizam um código discursivo pleno de fontes expressivas novas. É o que Anis (1999), parafraseando a definição de "norma locutória" de Vachek (1973), definiu como "norma scripto-conversacional". 5 
Efetivamente, são as novas motivações enunciativas (relações de amizade entre os interlocutores, atitudes lúdicas da conversa-escrita teclada, buscas de expressividade, emoção ou afetividade) desta nova esfera de vida social que criam uma variedade de linguagem - específica deste novo modo de comunicação - e provocam a emergência de novos gêneros do discurso ciberespacial.

Essas características linguageiras, semióticas, pragmáticas e discursivas, aliadas às ferramentas, aos suportes e aos dispositivos, tornam-se rotineiras como norma "scripto-conversacional", ajudam a quebrar as fronteiras entre a oralidade e a escrita, constituem mais uma evidência do nascimento de novos gêneros, que possuem uma nova entidade enunciativa, e apontam para um novo processo de leitura/escrita (compreensão/recepção e produção), principalmente se ligamos e aliamos essas questôes ao espaço enunciativo e à arquitetura hipertextual da/na internet: a virtualidade do texto informatizado e o modo de estruturação hipertextual das informaçōes.

3. O espaço enunciativo, a arquitetura hipertextual e a virtualidade do texto informatizado: implicações no ler/escrever

A internet é virtual, múltipla, multimidiática, heterogênea, multifacetada, não-linear, autônoma, desterritorializada, desmaterializada: um ciberespaço, um hiperespaço, uma entidade enunciativa nova. Ela permite uma escrita/leitura que não são mais limitadas geograficamente. Passamos de uma lógica linear para uma lógica multidimensionada, cuja relação de construção de sentido é múltipla no ciberespaço. O que a difere profundamente de um dicionário enciclopédico, que também permite aos leitores fazerem percursos indefinidamente diferenciados, "é a possibilidade que dão estes novos instrumentos de criação de novas relações 'ao gosto de cada um', de memorização de trajetos, de os percorrer, de bifurcar quando se julgar necessário, ou quando se sentir vontade" (Chappaz, 1993, p. 43).

É um espaço-tempo bastante diferente: "Um espaço aberto numa informação multidimensionada, desmaterializada, (...) e um tempo indefinido, ao mesmo tempo longo e curto" (Maurry, 2000, p. 22). Longo porque se trabalha "fora do tempo real", por meio do correio eletrônico principalmente, e curto em função da aceleração das trocas de "turnos" e do acesso aos recursos eletrônicos. 
Como se trata de um universo virtual, os textos escapam aos usuários porque não possuem ancoragem concreta e são abertos a múltiplas interpretações. Nesse universo ciberespacial virtual, novas formas e novos tipos de espaços são reinventados e adicionados. Entretanto não são apenas substituições, mas reconfigurações de paradigmas já existentes.

Esse tipo de universo, com suas idiossincrasias, exige do usuário o desenvolvimento de algumas habilidades ou competências para ler e escrever, já que se trata de uma escritura interativa em rede. O escritor e o leitor devem levar em conta a situação de comunicação em razão da leitura virtual e do modo de estruturação hipertextual das informações.

Essa organização interativa hipertextual, na qual há imbricações discursivas (links) que são diferentes das do discurso tradicional linear, oferece recursos que nos dão a possibilidade de construir superposições de discursos. Podemos, nesse espaço, "executar açôes como: procurar, escolher, fazer triagem, classificar, associar, comparar, religar, reorganizar, reformular, sintetizar etc." (Godinet, 2000, p. 33). Estas “operações" realizadas via navegação instrumentalizada são bastante complexas, até labirínticas, e os textos produzidos são diferentes, qualitativa e quantitativamente, com relação aos textos-papéis.

A estruturação enunciativa do texto impresso é linear e confundese com a ordem das páginas, ao passo que nos hipermídias a organização do espaço enunciativo não é mais única, mas toma a forma de uma rede, cujas páginas se associam a muitas outras via (hiper)palavras ou palavras/ expressões-chave, que se multiplicam na internet em todo tipo de sites.

Ancorado, pois, na informática, o hipertexto possui uma textualidade eletrônica virtual cujo espaço é outro e, por isso mesmo, vai além do texto de formato tradicional. Trata-se de um texto que podemos visualizar facilmente quando navegamos na internet. Segundo Barthes (1977), trata-se de um texto composto de blocos de palavras, ou de imagens, conectados eletronicamente, com múltiplos percursos, numa textualidade sempre aberta e infinita. $\mathrm{O}$ texto é um leque de significantes e não uma estrutura de significados. Não há começo, mas reversibilidade com todos os acessos possíveis.

Ao passo que o texto tradicional é um conjunto de parágrafos sucessivos, reunidos em partes ou em capítulos, que são lidos, comumente, do começo ao fim, um hipertexto é um conjunto de dados textuais que possuem um suporte eletrônico e que podem ser lidos de diversas ma- 
neiras e por diversos caminhos. Os dados são divididos em elementos ou nós de informação, como parágrafos. São os elementos marcados por ligações semânticas que permitem a passagem de uma parte à outra. Os nós são fisicamente "ancorados" em zonas do texto, ou como palavras ou como frases. O texto tradicional propõe ao leitor um percurso fixo, ao passo que o hipertexto dá ao leitor a opção de construir progressivamente um conjunto fugaz de elementos textuais, a seu bel-prazer.

As características do hipertexto (modularidade, virtualidade, multimodalidade, interatividade) revolucionaram a escrita e a leitura por causa da virtualidade, palavra que resume as potencialidades e as possibilidades oferecidas pela transformação de texto. Como produto, o hipertexto é uma fonte de consultas e de leitura, constituindo-se, portanto, em um conjunto de dados acessíveis à navegação anterior. Ou seja, ele é um material a ser explorado em profundidade, de maneira combinatória, arborescente e descendente, em que cada elemento textual contém uma porta de acesso a outros elementos (Godinet, 1993).

Se, de um lado, a hipertextualidade eletrônica foi uma grande revolução na comunicação e trouxe grandes vantagens no campo da produção, compreensão e circulação de novos tipos de texto, de outro, ela pode também trazer dificuldades nas práticas de leitura e escrita eletrônicas, provocadas pelas especificidades da virtualidade hipertextual. Segundo Godinet (2000), essas dificuldades se dão na segmentação do material em nós, na navegação semântica e também na navegação operacional.

Os (hiper)textos, portanto, são produtos verdadeiramente mais complexos que as formas textuais tradicionais em razão do conjunto de especificidades da hipertextualidade, com implicaçôes nas estratégias cognitivas de leitura e escrita.

\section{Conclusão}

O ciberespaço é realmente um novo território criado pelo homem e constitui uma nova esfera de produção de discurso. Contudo computador e internet não são um fim em si mesmos. Podemos dizer que os hipermídias estão na ponta do desenvolvimento tecnológico, tanto pelos instrumentos de escrita e pelos textos (biblioteca virtual) que oferecem quanto por sua relação social com o usuário. Eles são, ao mesmo tempo, instrumentos de escritura e de organização de conheci- 
mentos, e transformam o espaço de trabalho modificando as formas interativas, discursivas e linguageiras

A inter-relação homem-máquina altera as interações verbais e sociais e altera também as referências espaciais e temporais. Se entendermos a referenciação como "um processo de adaptação às condições espaciotemporais que caracterizam uma interação" (Vivier, 2001, p. 7), a produção, a compreensão e a pesquisa de (hiper)textos ou a comunicação mediada pelo computador vão apresentar características específicas: cognitivas, linguageiras, lingüísticas, discursivas, enunciativas e pragmáticas. Anis (2000) diz que o processamento de texto apareceu não como um instrumento a mais, mas sim como o instrumento que levou a uma evolução significativa da leitura e da escrita.

Quanto ao ler (compreensão) e escrever (produção), a utilização de novas tecnologias exige outras atitudes e posturas, ou novas competências cognitivas (utilização ou leitura do teclado, escrever com o teclado, leitura de menus, de ícones, palavras-chave, aprender o "navegar-ler" etc.). Isso não quer dizer que ler e escrever, hipertextualmente, são uma exclusividade da internet. A diferença entre o hipertexto, virtual, e o texto-papel não é o produto - o artefato empírico -, mas a construção textual, isto é, a textualidade de um e de outro, em que linearidade ou nãolinearidade é o resultado de um princípio de construção textual. Segundo Marcuschi (2000), a não-linearidade é uma técnica de produção no hipertexto e, no texto-papel, uma forma de recepção. A não-linearidade é, pois, inerente a esses sistemas tecnológicos que parecem exigir novas competências (meta)cognitivas: novas estratégias de navegação, de pesquisa de informação e de compreensão do escrito.

Portanto, os novos hipermídias são mais exigentes que os antigos no que se refere ao ler e escrever, tanto pelas ferramentas técnicas que oferecem como pelas novas práticas de escrita e de informaçóes ali presentes, e também pelos novos gêneros textuais, produtos desse novo espaço cibercultural. $\mathrm{O}$ computador oferece um espaço visualmente animado e complexo. A ferramenta mesmo é complexa. Mais que um espaço de escritura visual e físico oferecido por esta nova tecnologia, temos um espaço enunciativo no qual nascem/emergem novos gêneros textuais do discurso eletrônico, frutos de novas motivações sociais (interação virtual), de novas circunstâncias de comunicação (a comunicação eletrônica) e de novas ferramentas de comunicação e de produção de textos (o computador, o celular). 
Em suma, a banalização bem recente dessas formas de comunicação e de escrita/leitura, cujas interlocuções verbais se operam por via eletrônica, inscreve-se numa situação enunciativa física e social sui generis com conseqüências nas mutações tecnológicas, processuais e cognitivas do/no ler/escrever.

\title{
Recebido em fevereiro de 2004 e aprovado em março de 2004.
}

\section{Notas}

1. Esta organização em forma de "nebulosa" Bronckart (1999, p. 100) chamou de "intertexto", definido como o conjunto de gêneros de textos elaborado pelas geraçôes precedentes, tais como são utilizados e eventualmente transformados e reorientados pelas formaçôes sociais contemporâneas.

2. “(...) conjunto de técnicas informáticas que permitem o registro, a memorização, a correção, a atualização, a construção de página e a difusāo de textos” (Dicionário enciclopédico, 2000, p. 1.586. $2^{\mathrm{a}}$. col.)

3. Segundo Anis (2000, p. 60): “(...) ainsi les 'salons' miniteliens, communication de groupes en quasi direct, engendrent une forme linguistique plus déviant par rapport à l'écrit traditionnel que les dialogues, communication en différé interindividuelle. De même sur l'Internet, les corpus de chats, où la pression du direct et la dynamique de groupe sont comparables à celles des salons miniteliens, offrent à l'observateur plus de spécificités linguistiques que les corpus de courrier électronique.

Dans le même temps, on peut constater avec R. Panckhurst que 'l'illusion de synchronicité, l'exigence de la rapidité, la pauvreté de la forme textuelle 'brute' (...) font que l'on a recours à des types de fonctionnement typiques d'une situation de communication orale, et qui ne figurent pas (ou, en tous les cas, à un degré bien moindre, dans d'autres types d'écrits' et reconnaître avec F. Cusin- Berche que le courriel (courrier électronique) est un "écrit spontané hâtif'."

4. As abreviaçōes e o estilo telegráfico; as "caretinhas" (emoticons) são, muitas vezes, usadas com valores semiológicos não-verbais (por exemplo: :) = (;), indicando sorriso, alegria); o alongamento, a repetição de caracteres que podem, em certos casos, simular a entonação e, assim, conter uma informação paraverbal; fórmulas de abertura e de fechamento são reduzidas, quase que desaparecem; uso de "simulação" de trocas de turnos de fala com ajuda de "<...>"; uso de palavras registradas inteiramente em maiúsculas para indicar (gritar, ou falar alto) irritação, raiva.

5. "Um sistema de elementos lingüísticos que se manifestam graficamente e cuja função é de reagir a um estímulo dado (o qual em regra geral tem o caráter de urgência) de um modo dinâmico, ou seja, de uma maneira pronta e imediata, exprimindo não só o aspecto puramente comunicacional, mas também o aspecto emocional do usuário da linguagem, que reage". (Anis, 1999. Tradução nossa).

\section{Referências bibliográficas}

\author{
ANIS, J. (Dir.). Internet, communication et langue française. Paris: \\ Hermes, 1999.
}


ANIS, J. Modifications dans les pratiques d'écriture. Le Français Aujourd'hui, Paris, n. 129, p. 59-69, mar. 2000.

ANIS, J.; MARTY, N. (Org.). Lecture et écriture et nouvelles technologies. Paris: CNDP, 2000.

ANIS, J.; TEMPORAL-MARTY, N. (Dir.). Ecriture, informatique, pedagogies. Paris: CNDP, 1990.

BAKTHIN, M.M. Os gêneros do discurso. In: BaKHTin, M.M. Estética da criação verbal. São Paulo: Martins Fontes, 1994.

BARTHES, R. O prazer do texto. São Paulo: Perspectiva, 1977.

BRONCKART, J.-P. Atividades de linguagem, textos e discursos. São Paulo: EDUC, 1999.

CHAPPAZ, G. Copier... couper... coller... une nouvelle écriture? Cahiers Pédagogiques, Paris, v. 2, n. 311, p. 42-43, 1993. (Ecrire avec l'ordinateur)

CLÉMENT, J. Les écrivains, les écrivans et l'ordinateur. Cahiers Pédagogiques, Paris, v. 2, n. 311, p. 46-47, 1993. (Ecrire avec l'ordinateur)

ClÉMENT, J. L'adieu à Gutenberg. In: Crinon, J.; Gautellier, C. Apprendre avec le multimédia et internet. Paris, RETZ, 2001. p. 11-23.

COSTA, S.R. Oralidade e escrita e novos gêneros (hiper) textuais na internet. In: CONFERÊNCIA DE PESQUISA SOCIOCULTURAL, 3., 2000, Campinas. Campinas: UniCAMP/FE, 2000. (CDROM)

GODINET, H. L'hypertexte au lycée. Cahiers Pédagogiques, Paris, v. 2, n. 311, p. 267, 1993. (Ecrire avec l'ordinateur)

GODINET, H. Hypermédias et parcours labyrintiques. Vers une rhétoriqaue de l'ypertexte. Le Français Aujourd'hui, Paris, n. 129, p. 29-39, mar. 2000.

GOODY, J. The domestication of the savage mind. Cambridge: Cambridge University Press, 1997.

HUDRISIER, G.; HUDRISIER, H. Les enjeux culturels et didactiques de la lecture assistée par ordinateur. Le Français Aujourd'hui, Paris, n. 129, p. 40-49, mar. 2000.

MAINGUENEAU, D. Les termes clés de l'analyse du discours. Paris: Seuil, 1996. 
MARCUSCHI, L.A. O hipertexto como um novo espaço de escrita em sala de aula. In: Azeredo, J.C. (Org.). Lingua Portuguesa em debate. Petrópolis: Vozes, 2000. p. 87-111.

MAURRY, Y. Entre recherche documentaire et culture de l'information. Le Français Aujourd'hui, Paris, n. 129, p. 19-28, mar. 2000.

PANCKHURST, R Analyse linguistique assistée par ordinateur du courriel. In: ANIS, J. (Dir.). Internet, communication et langue française. Paris: Hermes, 1999. p. 55-70.

VACHEK, J. Written language. General problems and problems of English. The Hague: Mouton, 1973.

VUILLEMIN, A. L'informatisation des systèmes d'écriture. In: ANIS, J.; Temporal-Marty, N. (Dir.). Ecriture, informatique, pedagogies. Paris: CNDP, 1990. p. 28-32. 